\title{
PEMENUHAN KEBUTUHAN INFORMASI WISATA UNTUK KELUARGA MELALUI AKUN INSTAGRAM @FAMILYGOERS
}

\author{
Agustina Eka Putri ${ }^{1}$, Ute Lies Siti Khadijah ${ }^{1}$, Evi Novianti ${ }^{1}{ }^{1}$ Cipta Edyana $^{1}$, Heryadi Rachmat ${ }^{1}$ \\ ${ }^{1}$ Program Studi Magister Pariwisata Sekolah Pascasarjana Universitas Padjadjaran \\ agustina19001@unpad.ac.id, ute.lies@unpad@ac.id, evi.novianti@unpad.ac.id,cipta.endyana@unpad.ac.id, \\ heryadirachmat220@gmail.com
}

\begin{abstract}
ABSTRAK
Media sosial hadir dalam rangkaian kehidupan dan sudah menjadi kelaziman. Berbagai kalangan berbondong-bondong menggunakan perangkat smartphone dan menggunduh berbagai aplikasi termasuk aplikasi untuk bersosial media. Karena itu, media sosial dapat dilihat sebagai medium (fasilitator) online yang menguatkan hubungan antarpengguna sekaligus sebagai sebuah ikatan sosial. Para pengguna baselayer menggunakan aplikasi Instagram sebagai media untuk mendapatkan informasi mengenai penjualan baselayer. Biasanya para pengguna baselayer mem-follow (menjadi pengikut) dan mengunjungi akun -akun baselayer untuk melihat postingannya. Instagram sebagai salah satu media sosial yang dipilih dan digunakan ribuan bahkan jutaan orang dalam proses pencarian informasi yang dibutuhkannya dan adanya akun @ familygoers menjadi sumber informasi traveler untuk keluarga yang diharapkan sebagai acuan oleh para followers-nya dan pengguna Instagram pada umumnya untuk mengetahui dan menjadi referensi dalam pencarian informasi untuk kegiatan pariwisata baik untuk destinasi di dalam negeri maupun di luar negeri. Hasil dari penelitian ini adalah Penggunaan media sosial memungkinkan wisatawan untuk mengetahui secara singkat informasi - informasi dalam hal pariwisata, karena setiap wisatawan tersebut memiliki niat dan memiliki control terhadap kegiatan berwisata yang akan dilakukannya. Kemajuan pesat teknologi, khususnya media sosial juga memberikan perubahan pesat yang revolusioner dalam sector pariwisata, dengan banyaknya informasi di internet, calon wisatawan dapat menemukan informasi yang relevan dan memadai dalam membuat keputusan berwisata yang tepat dan sesuai dengan keinginannya.
\end{abstract}

Kata Kunci : Media Sosial, Instagram @falimygoers, Smart Traveler

\section{FULFILLMENT OF TRAVEL INFORMATION NEEDS FOR FAMILY THROUGH INSTAGRAM ACCOUNT @FAMILYGOERS}

\begin{abstract}
Social Media is present in the series of life and has become a rarfaith. Various circles using a smartphone device and use a variety of applications including applications for social media. Therefore, social media can be seen as a medium (facilitator) online that strengthens the relationship between users as well as a social bond. The users of Baselayer use the Instagram app as a medium to get information about the sale of Baselayer. Usually the users of Baselayer follow and visit the account - The accounts of Baselayer to see the posts. Instagram as one of the social media chosen and used by thousands even millions of people in the process of searching the information it needs and the existence of @familygoers account to be the source of the traveler's information for families that are expected to be a reference by his followers and Instagram users in general to know and be a reference in information search for tourism activities both for domestic and overseas destinations. The result of this research is the use of social media allows tourists to know briefly the information in terms of tourism, because each of these tourists have an intention and have control of the travel activities that will be done. The rapid advancement of technology, in particular social media also provides a revolutionary rapid change in tourism sectors, with a lot of information on the Intemet, prospective tourists can find relevant and adequate information in making the right travel decisions and according to their wishes.
\end{abstract}

Key words; Media Sosial, Instagram @falimygoers, Smart Traveler

\section{PENDAHULUAN}

Kehadiran media sosial dalam rangkaian kehidupan masyarakat sudah menjadi kelaziman. Beberapa tahun terakhir ramai orang -orang berbondong -bondong membeli perangkat telpon pintar atau smartphone tersebut dapat disematkan sebagai aplikasi atau fitur untuk bersosial media. Sebut saja Facebook, Twitter, Instagram dan Line.
Terlepas dari tujuan dan manfaat apa saja yang diperoleh setelah mendapat perangkat tersebut, fokusnya pada teknologi yang telah memberikan akses kepada seseorang untuk melakukan jejaring sosial (network society) tanpa batasan ruang dan waktu.

Dengan kehadiran new media atau media baru tersebut, tanpa disadari telah mempengaruhi banyak aspek kehidupan manusia. Salah satunya dampak banjir informasi. Media baru pengguna bisa 
berinteraksi, baik antar pengguna itu sendiri maupun dengan prosedur konten media. Di media sosial, informasi menjadi komoditi yang dikonsumsi oleh pengguna. Aktivitas ini kita kenal dengan jejaring sosial atau network society. Jejaring sosial merupakan bagian yang tidak dapat di pisahkan dari manusia (Holmes, 2005). Media sosial menurut Mandiberg dalam Nasrullah (Nasrullah, 2018) adalah media yang mewdahi kerjasama di antara pengguna yang menghasilkan konten (usery-generatedcontent).

Kemudian media sosial adalah platform media yang memfokuskan pada eksistensi pengguna yang memfasilitasi mereka dalam beraktivitas maupun berkolaborasi. Karena itu, media sosial dapat dilihat sebagai medium (fasilitator) online yang menguatkan hubungan antarpengguna sekaligus sebagai sebuah ikatan sosial (Nasrullah, 2018)

Instagram merupakan satu dari sekian banyak media sosial yang menjangkau penggunanya untuk melakukan aktivitas komunikasi dan informasi di dunia maya. Brand Development lead Instagram APAC Paul Webster mengungkapkan "Indonesia sendiri adalah salah satu negara dengan jumlah pengguna Instagram terbanyak dengan 89 persen. Instagrammers yang berusia 18-34 tahun mengakses Instagram setidaknya seminggu sekali". "Instagrammers mayoritas anak muda, terdidik, dan mapan. Rata - rata mereka berusia 18-24 tahun sebanyak 59 persen, usia 34-44 tahun 11 persen, dan yang berusia 44- 45 tahun 30 persen. Pengguna Instagram permpuan yang paling aktif sebanyak 63 persen dan laki -laki 37 persen," pungkas Paul (Mailanto, 2016).

Informasi di media sosial Instagram sangat mudah tersebar karena siapapun dapat mengakses dan menggunakan Instagram, setiap postingan yang ada di Instagram pun dapat dengan mudah diteruskan (share) oleh setiap pengguna dan membuat siapapun dapat melihatnya (Yoeti, 2017). Para pengguna baselayer menggunakan aplikasi Instagram sebagai media untuk mendapatkan informasi mengenai penjualan baselayer. Biasanya para pengguna baselayer memfollow (menjadi pengikut) dan mengunjungi akun akun baselayer untuk melihat postingannya.

Jejaring sosial online adalah jenis komunikasi virtual yang memungkinkan orang untuk terhubung satu sama lain. Konsep ini muncul dari kebutuhan dasar manusia untuk tetap bersama dalam kelompok membentuk komunitas. Michael Wesch, antropolog budaya di Kansas State University, membandingkan masyarakat suku dengan jejaring sosial online. Seperti budaya suku, dalam Facebook orang memproyeksikan identitas mereka dengan menunjukkan hubungan mereka satu sama lain. Anda mendefinisikan diri Anda dalam hal siapa teman Anda (Whreight, 2002) Wikipedia mendefinisikan layanan jejaring sosial sebagai platform online yang fokus membangun dan mencerminkan jejaring sosial atau hubungan sosial di antara orang-orang yang memiliki minat dan kegiatan yang sama.

Situs jejaring sosial, email, pengiriman pesan instan, situs berbagi video dan foto dan posting komentar adalah semua alat yang membantu orang untuk berkomunikasi dan bersosialisasi satu sama lain (Mahendra, 2017). Situs jejaring sosial pertama SixDegrees.com diluncurkan pada tahun 1997. Ini memungkinkan pengguna untuk membuat profil, daftar teman-teman mereka dan menjelajahi daftar teman) (Beer, 2008). Mulai dari 1997 hingga 2010 ada sekitar 1,5 miliar pengguna situs jejaring sosial (Mahendra, 2017). Orang-orang bergabung dengan situs jejaring sosial karena memberi mereka kesempatan untuk mengekspresikan pandangan mereka, rasa kemandirian dan harga diri. Ini hanya cara klik untuk membuat profil virtual dan terhubung dengan jutaan pengguna di seluruh dunia, menjadi lebih menarik karena Anda dapat tetap terhubung dengan teman lama dan anggota keluarga.

Hal ini penulis tertarik untuk melakukan penelitian. Instagram sebagai salah satu media sosial yang dipilih dan digunakan ribuan bahkan jutaan orang dalam proses pencarian informasi yang dibutuhkannya dan adanya akun @familygoers menjadi sumber informasi traveler untuk keluarga yang diharapkan sebagai acuan oleh para followersnya dan pengguna Instagram pada umumnya untuk mengetahui dan menjadi referensi dalam pencarian informasi untuk kegiatan pariwisata baik untuk destinasi di dalam negeri maupun di luar negeri.

Salah satu akun yang menawarkan informasi tentang kegiatan pariwisata yang menarik perhatian penulis dan dan memberikan banyak pilihan adalah milik seorang bloger dengan username akun Instagram @ familygoers. Dengan segala kemudahan yang ditawarkan teknologi, maka segala bentuk informasi mengenai baselayer juga terus berkembang. Mulai dari tren yang sedang booming, berbagai media shopping, bermacam ragam baselayer yang dengan mudah kita akses untuk kemudian muncul keinginan untuk membeli, didukung oleh keunggulan media sosial Instagram yang memang atraktif dan interaktif yang menjadi tren baselayer sedang in akan segera dengan cepat berkembang di kalangan pria bahkan wanita yang tentunya menggunakan smartphone di kehidupan sehari-harinya.

Penelitian ini untuk melihat Ada stigma bahwa ketika Anda punya anak, bepergian tidak akan pernah sama seperti dulu. Bepergian dengan mereka bukanlah suatu kesenangan, itu hanya membawa tugas-tugas rumah Anda ke luar. Ya, itu tidak hanya bepergian, memiliki anak-anak mengubah hidup Anda. Anda orang yang berbeda. Meskipun demikian, menjadi 
orang tua dengan anak-anak tidaklah mengerikan. Itu tidak berarti mengasuh anak adalah sesuatu yang harus Anda hindari. Memang ada sukacita dalam mengasuh anak. Begitu juga bepergian dengan anak-anak. Semua orang tahu itu sangat menantang ketika Anda bepergian dengan anak-anak Anda ke mana saja. Anda tidak lagi memikirkan diri sendiri, preferensi, gaya perjalanan, dan anggaran Anda. Akan lebih mahal dan lebih rumit karena Anda harus mempertimbangkan kebutuhan dan preferensi anak-anak Anda. Namun, tidak sengsara, Anda masih bisa bersenang-senang saat bepergian dengan anak-anak.

Meski begitu, banyak penelitian telah membuktikan manfaat bepergian sebagai sebuah keluarga. Itu dapat membangun hubungan keluarga yang lebih kuat. Ini memberi Anda berdua, orang tua dan anak-anak, pendidikan dan pengalaman global. Ini memperkaya kehidupan setiap orang. Dan masih banyak lagi. Masyarakat yang menyukai traveling juga memahami pro dan kontra bepergian dengan anakanak dan berniat untuk mendorong keluarga untuk melakukan perjalanan lebih banyak. Informasi yang di dalamnya menyajikan platform untuk menyatukan para pelancong keluarga untuk berbagi kiat, rekomendasi, dan kisah perjalanan dari mana saja dengan gaya perjalanan apa pun.

\section{METODE}

Penelitian ini menggunakan pendekatan kualitatif dengan metode studi kasus. Karena peneliti menemukan suatu kasus yang unik untuk dianalisis terkait analisis media social untuk pencarian informasi wisata keluarga dan memerlukan pengumpulan data secara mendalam dan detail. Hal ini sejalan dengan apa yang dijelaskan oleh (Creswell, 2013). Studi kasus menekankan pada penelitinya mengeksplorasi kehidupan nyata, sistem terbatas kontemporer (kasus) atau beragam sistem terbatas (berbagai kasus), melalui pengumpulan data yang detail dan mendalam yang melibatkan beragam sumber informasi atau sumber informan majemuk (misalnya : pengamatan, wawancara, bahan audiovisual, dokumen dan berbagai laporan). Tipe studi kasus pada penelitian ini adalah studi kasus intrinsik karena hanya memfokuskan pada kasus tersebut (yang dianggap unik).

Pada penelitian ini untuk menentukan informan menggunakan sampling purposive. Menurut (Creswell, 2013) sampling purposeful Adalah memilih informan yang akan diteliti, karena dapat memberikan informasi secara spesifik kepada peneliti tentang pemahaman problem dalam riset. Dalam penelitian ini peneliti memilih informan dari pihak-pihak yang tergabung dalam penyebaran informasi wisata untuk keluarga. Responden yang oleh penulis dijadikan sebagai key informan berdasarkan pertimbangan sebagai berikut :

1. Follower aktif @ familygoers

2. Terlibat langsung dalam pelaksanaan kegiatan@familygoes

3. Melakukan kegiatan wisata melalui rekomendasi dan informasi yang ditayangkan baik dalam blog@familygoers maupun ig @ familygoes

4. Admin@familygoes sebanyak 1 orang

\section{HASIL DAN PEMBAHASAN}

Banyak informasi yang didapatkan dalam melihat peran media sosial dalam pariwisata untuk keluarga. Untuk menghubungkan media sosial dalam pariwisata dan untuk pariwisata keluarga, penelitian ini membahas berbagai media social memberikan informasi sebagai bahan pertimbangan untuk keputusan melakukan kegiatan pariwisata dengan kelurga. Pariwisata mengambil arah yang berbeda dalam hal pariwisata keluarga, termasuk kesadaran, pendidikan, interaksi sosial, kontribusi ekonomi, dan perubahan sosial, dengan syarat keterlibatan proses pencarian informasi yang sesuai. Untuk meningkatkan pariwisata keluarga, media sosial dianggap sebagai pilihan pertama, dengan potensi dampak yang besar pada menarik wisatawan Studi sebelumnya telah menunjukkan hubungan yang kuat antara media sosial dan pariwisata, di mana pariwisata memiliki dampak positif pada kondisi sosial dan ekonomi daerah pedesaan. Wisatawan terutama memilih berbagai tujuan di daerah pedesaan karena iklan media sosial. Media sosial memainkan peran penting ketika mencari informasi dan memilih tujuan perjalanan, bersama dengan pengambilan keputusan wisatawan di semua tahap tur atau perjalanan.

Penggunaan media sosial oleh konsumen telah memungkinkan industri pariwisata untuk memasuki era baru. Karena peran signifikan yang dimainkan oleh media sosial dalam membentuk sikap konsumen terhadap pariwisata keluarga, banyak negara di dunia telah memberikan perhatian khusus pada promosi media sosial dalam masyarakat mereka. Perilaku turis telah berubah sepenuhnya karena ketersediaan media sosial. Media sosial telah memungkinkan wisatawan untuk menemukan informasi ringkas. Dalam hal pariwisata, penggunaan media sosial memiliki dampak langsung, karena setiap wisatawan memiliki niat khusus, dan mencari kontrol atas kegiatannya. Penggunaan media sosial memungkinkan wisatawan untuk mengontrol aktivitas mereka. Juga, kemajuan pesat teknologi dan koneksi konsumen-internet telah membawa perubahan revolusioner di sektor pariwisata. Karena banyaknya informasi di internet, konsumen harus dapat menemukan informasi yang 
relevan dan memadai untuk membuat keputusan yang lebih baik secara tepat waktu.

Ketersediaan berbagai alat web telah membuat wisatawan mandiri dan memberi mereka beberapa alternatif dalam hal pilihan tempat untuk dikunjungi. Mengenai mengapa media sosial digunakan di sini untuk mengukur perilaku wisatawan, sebagian besar disebabkan oleh rasa tidak aman; hari-hari ini, mencari informasi di situs web tampaknya berisiko, sehingga wisatawan lebih suka atau lebih mempercayai media sosial dan aplikasi media lainnya [3,36]. Jumlah data yang lebih besar yang tersedia di situs web yang berbeda juga dapat menciptakan masalah untuk penggunaan sumber daya yang optimal.

Secara keseluruhan, penelitian ini dilakukan dengan pandangan bahwa media massa, dan terutama media sosial, dapat berkontribusi pada pariwisata terutama untuk pencarian informasi yang mempengaruhi pengambilan keputusan. Komunikasi media memainkan peran agen untuk meningkatkan aliran informasi dan meningkatkan pengambilan keputusan. Media massa juga dapat dengan mudah menjangkau orang-orang di komunitas terpencil. Studi ini mengungkapkan bahwa media sosial memberikan kontribusi langsung ke pariwisata khusus untuk keluarga dalam berbagai tahap yang berbeda sesuai dengan cara / tahapan di mana wisatawan dan konsumen dalam kebiasan mereka untuk menggunakan media sosial.

\section{SIMPULAN}

Hadirnya Instagram dan media sosial lainya memberikan kontribusi positive sebagai agen dari sebuah aliran informasi pariwisata. Banyaknya calon wisatawan yang terlebih dahulu mencari informasi mengenai tempat wisata yang akan dikunjungi, menjadi budaya baru pada wisatawan. Penggunaan media sosial memungkinkan wisatawan untuk mengetahui secara singkat informasi - informasi dalam hal pariwisata, karena setiap wisatawan tersebut memiliki niat dan memiliki control terhadap kegiatan berwisata yang akan dilakukannya. Kemajuan pesat teknologi, khususnya media sosial juga memberikan perubahan pesat yang revolusioner dalam sector pariwisata, dengan banyaknya informasi di internet, calon wisatawan dapat menemukan informasi yang relevan dan memadai dalam membuat keputusan berwisata yang tepat dan sesuai dengan keinginannya. Hal tersebut memberikan berbagai informasi dan alternative terbaik dalam pilihan tepat dan kesesuaian kebutuhan berwisata yang sesuai dengan keperluan dan keinginan calon wisatawan.

\section{DAFTAR PUSTAKA}

Beer, D. D. (2008). Social network (ing) sites... revisiting the story so far: A response to danah boyd \& Nicole Ellison. Journal of ComputerMediated Communication, 13(2), 516-529.

Creswell, J. (2013). Penelitian kualitatif dan desain riset. (S. Zuhri kudsi, Ed.) (3rd ed.). Indonesia: Pustaka pelajar.

Handani, S. W., Suyanto, M., \& Sofyan, A. F. (2016). Penerapan konsep gamifikasi pada e-learning untuk pembelajaran animasi 3 dimensi. Telematika, 9(1).

Holmes, D. (2005). Communication Theory Media, Technology, Society. Communication Theory. Thousand Oaks,: SAGE Publications, Ltd.

Kaplan, A. M., \& Haenlein, M. (2010). Users of the world, unite! The challenges and opportunities of Social Media. Business Horizons, 53(1), 5968.

Mahendra, B. (2017). EKSISTENSI SOSIAL REMAJA DALAM INSTAGRAM (SEBUAH PERSPEKTIF KOMUNIKASI). Jurnal Visi Komunikasi, 16(1), 151-160.

Nasrullah, R. (2018). Riset Khalayak Digital : Perspektiv Khalayak Media Sosial dan Realitas virtual di media sosial. Sosioteknologi, 17(2). Retrieved from https://media.neliti.com/media/publications/261 112-none-87405614.pdf

Porter, M. E. (1996). What is strategy. Published November.

Tsouli, D. (2018). SOCIAL MEDIA AS SOURCE FOR CITIES REPUTATION: EVIDENCE FROM TOP RANKED CITIES. Journal of Academic Research in Economics (JARE), 10(1), 132-142.

Whreight, J. (2002). Life Spand Development. Jakarta: Erlangga.

Yoeti, E. (2017). Perencanaan dan Pengembangan Pariwisata. Jakarta: Pradya Paramita.

Yusuf, P. M. (2010). Teori dan Praktik Penelusuran Informasi (informasi Retrieval).

Zook, M., Graham, M., \& Boulton, A. (2015). Crowd-sourced augmented realities: Social media and the power of digital representation. In Mediated geographies and geographies of media (pp. 223-240). Springer. 